\title{
ESTO/ESO, QUE X/ DE QUE X EN CONTRASTE. DEL SIGNIFICADO EVIDENCIAL PERCEPTIVO AL SIGNIFICADO EVIDENCIAL CITATIVO
}

\author{
Maria Marta García Negroni y Manuel Libenson \\ Universidad de San Andrés - Universidad de Buenos Aires - CONICET \\ mgarcianegroni@udesa.edu.; armlibenson@udesa.edu.ar
}

\begin{abstract}
Resumen
Este artículo busca poner de manifiesto, en primer lugar, el desplazamiento semánticopragmático que, desde el significado propio de dos pronombres neutros con valor deíctico espacial, esto y eso, se produce hacia un significado evidencial perceptivo directo (esto/eso, que $X$ ) y desde allí hacia una lectura evidencial citativa (esto/eso de que X). Para dar cuenta de este movimiento desde la marcación de la evidencialidad directa a la de la evidencialidad indirecta, se realizará un análisis contrastivo entre diferentes conjuntos de enunciados que contienen estos dos grupos de marcadores.

En segundo lugar, buscaremos explicitar que las diferencias semánticas en este continuum de significados evidenciales tienen relación necesaria con la especificidad de las instrucciones polifónicas (Ducrot, 1984) contenidas en las estructuras analizadas. Esto significa que el empleo de cada una de ellas contribuye a representar semánticamente una situación $x$ como surgida de cierto tipo de evidencia $z$, al mismo tiempo que pone en escena diferentes perspectivas y posicionamientos subjetivos a partir de los cuales dicha evidencia aparece modalizada por el sujeto de la enunciación.
\end{abstract}

PALABRAS CLAVE: pronombres demostrativos neutros, evidencialidad, polifonía.

\begin{abstract}
This paper seeks to show, firstly, the semanticpragmatic movement that goes from the proper meaning of two Spanish neutral pronouns with deictic spatial value, esto and eso, to a direct perceptual evidential meaning (esto/eso, que X) and, from there, to a quotative evidential interpretation (esto/eso de que X). To account for this passage from direct to indirect evidentiality, this paper shows a contrastive analysis between different set of utterances containing these two groups of evidential markers.

Secondly, the analysis shows that the semantic differences in the continuum of evidential meanings are necessary related to the specification of polyphonic instructions (Ducrot, 1984) contained in the signification of each marker. This means that the use of esto/eso, que $X /$ de que $X$ contributes to represent semantically an $x$ situation as arising from certain type of evidence $z$, while at the same time it stages different points of view and subjective perspectives from which such evidence is modalized by the discursive subject in charge of the enunciation.
\end{abstract}

KEYWORDS: neutral demonstrative pronoun, evidentiality, polyphony.

\section{Introducción ${ }^{1}$}

Las estructuras de las que nos ocuparemos en este artículo, y que ejemplificamos en (1) a (4), han sido relativamente poco estudiadas en las gramáticas, donde solo aparecen

\footnotetext{
${ }^{1}$ El presente trabajo forma parte de proyecto UBACyT 20020100100069 (Subjetividad y prácticas discursivas: acerca de las teorías no unicistas del sujeto y no veritativas de las significación), dirigido por María Marta García Negroni en el Instituto de Lingüística de la Universidad de Buenos Aires.
} 
tratadas, tangencialmente, en las secciones correspondientes a los estudios sobre la deixis y los pronombres demostrativos neutros. En términos generales, tampoco han sido objeto de reflexión en los estudios específicos sobre partículas discursivas.

(1) [Contexto situacional: diálogo entre dos amigos durante un viaje en automóvil por la ciudad]

Pero ¿a vos qué te molesta?

Esto [gesto ostensivo a montículo de bolsas de basura], que saquen la basura en cualquier momento.

(2) [Contexto situacional: diálogo entre una mujer (B) y su marido (A), mientras preparan las maletas para un viaje de vacaciones]

A-. Estás muy callada. ¿Hay algo que te tenga mal?

B-. Eso [señala un montón de ropa tirada del marido], que el desorden sea permanente en esta casa.

(3) [Contexto situacional: discurso parlamentario en Cámara de Senadores]

No voy a reiterar esto de que ya no tenemos tiempo de discutirlo, de hacer modificaciones, como ya dijeron en otras ocasiones los señores senadores.

(4) [Contexto situacional: un padre pide explicaciones a su hijo]

¿Cómo es eso de que te vas mañana?

En la Gramática descriptiva de la lengua española (1999), y en el apartado referido a los demostrativos neutros, Eguren solo indica que a diferencia de los demostrativos concordados, los neutros pueden ir acompañados de modificadores típicamente nominales y en ese sentido se asemejan al artículo neutro en algunos de sus usos. Por su parte, la Nueva gramática de la lengua española (2010) solo se detiene en los sintagmas esto/eso de $\mathrm{X}$, a los que describe como construcciones apositivas formadas con de seguido de un segundo segmento que puede ser tanto una estructura nominal (cf. 5),

(5) Esto de la antipsiquiatría vino a escarbar en los temas de la locura.

como una estructura oracional (cf. 6),

(6) No es malo eso de ir a la plaza con dos alicientes.

Con respecto a las diferencias de significado de las formas esto/eso/aquello, la Nueva gramática señala que «en las series ternarias la distancia respecto del centro deíctico no es tanto física como perceptiva o valorativa» (RAE, 2010: 1282) y agrega que, si bien es cierto que algunos hablantes pueden utilizar indistintamente uno $\mathrm{u}$ otro de estos demostrativos, el empleo de cada uno de ellos suele poner en evidencia grados de implicación, solidaridad o empatía diversos. La Nueva gramática agrega que «se extienden estos juicios - diferencia perceptiva para unos hablantes y neutralización para otros- en pares como \{esto eso\} que acabo de decir. En el primer caso, es relevante la proximidad relativa que el que habla quiera establecer con sus palabras anteriores, más que el tiempo real que haya transcurrido desde que las emitió» (RAE, 2010: 1282). 
En relación con los estudios sobre partículas o marcadores del discurso, y hasta donde sabemos, solo en el Diccionario de partículas, de Santos Río (2003), se incluye una entrada para eso de que $X$ (pero no para esto de que X). Santos Río caracteriza esta estructura como una fórmula reactiva deíctico-anafórica con la que «se replica a cierto dicho que acaba de proferir el interlocutor» para rechazar o problematizar el «hecho o dato aportado que, ecoicamente, se recoge en O» (Santos Río, 2003: 371).

Tal como se constata, los distintos tratamientos reseñados dan cuenta de los rasgos deícticos y modales involucrados en las estructuras que nos ocupan. Dejan de lado, sin embargo, un aspecto que, a nuestro entender, resulta central para la descripción del semantismo de estas formas, a saber: la enunciación de esto/eso, que X/ de que $X$ muestra un locutor que aparece representado como si se apoyara necesariamente en un conocimiento procedente de una fuente directa o indirecta. Se trata así de verdaderos marcadores de evidencialidad que, a partir del significado deíctico y modal de los pronombres neutros esto y eso, permiten codificar distintos tipos de significado evidencial ${ }^{2}$. Nuestra hipótesis sostiene que esos significados —que van desde la codificación de una fuente directa perceptiva hasta la codificación de una fuente indirecta, un discurso citado o evocado - se relacionan, por un lado, con la pérdida gradual del significado deíctico (a favor del modal) en los pronombres y, por el otro, con el tipo de estructura apositiva (explicativa o especificativa) que les sigue.

Con el fin de ponerlo en evidencia y luego de una breve presentación de nuestro enfoque teórico-metodológico $(\$ 2)$, analizaremos, en primer lugar $(\$ 3)$, las estructuras esto/eso, que $X$, y describiremos su empleo como marcadores tanto de evidencialidad directa (perceptiva) como indirecta (anafórico-citativa). En segundo lugar $(\$ 4)$, nos detendremos en el estudio de la estructura evidencial citativa esto/eso de que $X$. Finalmente, en un último apartado $(\$ 5)$, introduciremos algunas consideraciones finales.

\section{El significado evidencial a la luz de la teoría polifónica de la enunciación}

En cuanto a nuestra perspectiva teórico-metodológica, asumimos el enfoque no logicista y no referencialista de la significación que propone la teoría de la polifonía enunciativa (Ducrot, 1984, 2004). Siguiendo los presupuestos de esta semántica enunciativa, nuestro análisis se opone a la idea según la cual la significación del lenguaje está constituida por aspectos informativos o de orden cognitivo. Por ello, rechaza la hipótesis de que el estudio del lenguaje implica evaluar las proposiciones en términos de valores de verdad o de perfilamiento intencional de la información por parte del sujeto hablante. Nuestra concepción del sentido se aleja, en efecto, de toda visión que considere los valores semánticos en términos de elecciones siempre voluntarias de un

\footnotetext{
${ }^{2} \mathrm{Al}$ respecto, resulta interesante destacar que, de acuerdo con Aikhenvald (2004: 275), gran parte de los evidenciales en las lenguas que los tienen gramaticalizados como morfemas obligatorios tiene su origen en deícticos locativos. Tal es el caso, según la autora, del morfema que marca el origen de la información en un hearsay en la lengua sisaala (de Burkina Faso) y que proviene de un locativo demostrativo equivalente al español esto.
} 
único sujeto intencional. En otras palabras, impugna toda concepción monológica del funcionamiento del lenguaje $\mathrm{y}$ adopta, en cambio, una perspectiva dialógica $\mathrm{y}$ polifónica, es decir, una caracterización del sentido del enunciado como una calificación o dramatización de su propia enunciación y que consiste en la puesta en escena de una multiplicidad de voces y puntos de vista que se expresan a través de ella (Ducrot, 1984). Vehiculadas por la gramática, el léxico o incluso la prosodia, las instrucciones polifónicas obligan así al interpretante del enunciado a localizar si hay uno o más responsables de la enunciación (i.e., el locutor en tanto tal, L), a reconocer los distintos puntos de vista introducidos en ella, a identificar eventualmente su origen y a determinar la actitud o posicionamiento enunciativo que el locutor adopta frente a ellos (i.e., rechazo, aprobación, acuerdo, indiferencia).

A la luz de esta semántica polifónica, buscamos dar cuenta de un conjunto de fenómenos que manifiestan significados evidenciales sin hacer intervenir principios epistemológicos y conceptos frecuentemente utilizados en los estudios sobre evidencialidad $^{3}$ : el sujeto hablante como origen del sentido, el discurso como codificación de información verificable e identidad o cuasi-identidad entre la intención del sujeto empírico y el significado comunicado ${ }^{4}$. Como se recordará, la evidencialidad suele definirse como el dominio semántico relacionado con la codificación de la fuente de información del emisor real y con la especificación de qué tipo de fuente (directa o indirecta) se trata (Aikhenvald, 2004). Para estos enfoques, el conocimiento de procedencia directa se representa en la gramática como adquirido por medio de una percepción sensible originada en alguno de los sentidos del hablante (vista, oído y olfato fundamentalmente). El modo de obtención del conocimiento indirecto, por su parte, puede ser tanto producto de una inferencia razonada como de la cita de un discurso ajeno (Anderson, 1986; Willet, 1988).

Desde nuestra perspectiva, en cambio, el significado evidencial, que en español aparece mostrado a través de ciertos aspectos de la morfología, la sintaxis, el léxico o la prosodia, debe definirse como la representación que el enunciado da del punto de vista o discurso sobre el que se funda la enunciación actual o parte de ella (i.e., punto de vista evidencial) y que exige la búsqueda e identificación de su origen. Dicho de otro modo, las instrucciones polifónicas relacionadas con ese significado evidencial obligan a interpretar la enunciación como fundada en un punto de vista (una constatación, una cita, una inferencia) cuyo origen (la percepción, un discurso) exige ser identificado para poder acceder al sentido completo del enunciado. Así, en casos como (7),

\footnotetext{
${ }^{3}$ Como es sabido, el estudio de la evidencialidad suele dividirse en dos grandes aguas: entre las investigaciones que, inspiradas en los trabajos precursores de Boas y Jakobson, la definen en sentido restringido, como una categoría gramatical obligatoria que codifica el origen de la información del hablante y su modo de obtención (Anderson, 1986; Aikhenvald, 2004; Willet, 1988, entre otros) y aquellas otras que, en sentido amplio, consideran evidencial no solo la marcación de la fuente del conocimiento obtenido sino también, y de manera fundamental, la actitud modal o postura epistemológica que adopta el hablante frente a ella en el marco de una interacción discursiva (Chafe, 1986; Reyes, 1994; Mushin, 2001; Bermúdez, 2005; Carranza, 2007; entre otros)

${ }^{4}$ Para un estudio sobre los límites del referencialismo y del intencionalismo lingüístico, podrá consultarse García Negroni, Libenson, Montero, 2014.
} 


\section{(7) La encontré cambiada a María.}

el punto de vista evidencial sobre el que se funda la enunciación se representa como si fuese el resultado de una constatación que obliga a buscar su origen en la percepción directa de una determinada situación anterior (cf. el perfecto simple en el verbo encontrar). En el caso de (8), en cambio,

(8) [De amigo A a amigo B, mientras mira los cuadros que se encuentran colgados en la pared de la casa de B]

¿Así que te gusta Picasso?

por la presencia del marcador así que, la enunciación se representa como fundada en una inferencia, es decir, en una evidencia indirecta, cuyo origen es, al igual que en (7), la percepción. Ahora bien, para poder establecer con claridad la diferencia entre (7) y (8), debe distinguirse el origen del punto de vista evidencial del modo en que este opera como fundamento de la enunciación actual en la que efectivamente aparece evocado. Si bien, de manera similar a lo que ocurre en los casos de evidencialidad directa, toda inferencia puede representarse a sí misma como surgida del objeto de una determinada percepción (aunque no exclusivamente), no deben confundirse las efectos de sentido que, en un caso y en otro, surgen de la representación que el enunciado brinda de su propia enunciación. Si en los casos de evidencialidad directa la búsqueda del origen en la percepción obliga al interpretante a asumir que el enunciado se encuentra surgido de una constatación directa de una situación determinada, y en esto consiste precisamente la cualificación que el enunciado da de su enunciación, en los casos de inferencia, el origen perceptivo se representa de manera indicial, como si fuese el fundamento de un tipo de razonamiento conjetural, hipotético.

Por último, en casos de evidencialidad indirecta citativa, como el ejemplificado (9),

(9) Habría un aumento del dólar en los próximos días.

es posible constatar que el punto de vista evidencial, fundante de la enunciación actual, se representa como si fuese una cita cuyo origen es un discurso previo, en este caso, un rumor (cf. presencia del condicional habría).

El análisis cualitativo que llevaremos a cabo en lo que sigue se basa en un corpus de ejemplos reales, tanto escritos como orales, procedentes del Corpus de Referencia del Español Actual, de la RAE, del Corpus del español, desarrollado por Mark Davies, de un corpus oral propio así como de sitios de Internet de habla castellana.

\section{Esto/eso, que $X$ : significados evidenciales perceptivo y citativo}

\subsection{El evidencial directo esto/eso, que $X$}

Comencemos por un primer caso en el que el pronombre neutro aparece seguido de una aposición explicativa.

A modo de ejemplo, consideremos nuevamente (1) y (2): 
(1) [Contexto situacional: diálogo entre dos amigos durante un viaje en automóvil por la ciudad]

A-. Pero ¿a vos qué te molesta?

B-. Esto [gesto ostensivo a montículo de bolsas de basura], que saquen la basura en cualquier momento.

(2) [Contexto situacional: diálogo entre una mujer (B) y su marido (A), mientras preparan las maletas para un viaje de vacaciones]

A-. Estás muy callada. ¿Hay algo que te tenga mal?

B-. Eso [señala un montón de ropa tirada del marido], que el desorden sea permanente en esta casa.

Como puede observarse, para acceder al sentido de las réplicas en (1) y (2) (Esto, que saquen la basura en cualquier momento y Eso, que el desorden sea permanente en esta casa) debe reconocerse que la representación discursiva vehiculada por la aposición explicativa $X$ (que saquen la basura en cualquier momento o que el desorden sea permanente en esta casa) se presenta como surgida de un percepción directa constatable -en este caso, visualmente- de una determinada situación, y ello precisamente en virtud de la presencia del deíctico demostrativo esto/eso, acompañado de algún signo ostensivo (un movimiento de la mano, de la mirada o de la cabeza). En efecto, si en lugar de Esto, que saquen la basura en cualquier momento o de Eso, que el desorden sea permanente en esta casa, la réplica de B hubiera sido Que saquen la basura en cualquier momento o Que el desorden sea permanente en esta casa, no habría habido ninguna instrucción de búsqueda del origen del punto de vista con el que el locutor (L) califica la situación de la que se trata. La ocurrencia de esto/eso acompañada del gesto corporal de señalamiento en (1) y (2) obliga, en cambio, a identificar un punto de vista evidencial directo $y$, en consecuencia, a buscar su origen en la representación del entorno perceptivo de la situación de enunciación.

Ahora bien, la lectura evidencial directa, y no meramente deíctica ${ }^{5}$, debe relacionarse con la estructura sintáctica (núcleo nominal deíctico + aposición explicativa) en la que esto/eso aparecen incorporados. Como es sabido, las aposiciones explicativas mantienen una relación de equivalencia semántica con el núcleo de la cláusula nominal que modifican. Pero, en casos como los de (1) y (2), y dada la presencia del deíctico neutro, núcleo y aposición se encuentran en una relación de «mutua afectación semántica». En términos polifónicos, las aposiciones explicativas contienen una instrucción semántica que obliga a interpretarlas como equivalentes al sentido vehiculado por el punto de vista asociado al núcleo de la cláusula nominal (i.e., esto/ eso, que remiten a un referente actual). Y viceversa, el sentido vehiculado por el punto de vista puesto en escena por la enunciación de esto/eso (deícticos demostrativos neutros con función ostensivoreferencial) debe ser reinterpretado como equivalente al punto de vista vehiculado por la representación discursiva $X$, materializada en la aposición explicativa. En otras

\footnotetext{
${ }^{5}$ A diferencia de los ejemplos (1) y (2) que vehiculan puntos de vista evidenciales, en enunciados del tipo Esto no me gusta y en ${ }_{¿} M e$ das eso?, los pronombres neutros esto y eso tienen un empleo deíctico puro que obliga a localizar un referente extralingüístico.
} 
palabras, el objeto de la deixis debe reinterpretarse como representación discursiva (y no como mero señalamiento actual de un referente extralingüístico) y la representación discursiva $X$ debe leerse como originada deícticamente ad-oculos. Así, esta operación de mutua afectación semántica, propia del funcionamiento de estas estructuras sintácticas es, precisamente, la que habilita la lectura evidencial directa de Esto/eso, que X.

Ahora bien, si las instrucciones de sentido contenidas en (1) y (2) exigen el reconocimiento de ese significado evidencial directo, la diferencia entre ambos se relaciona con el contenido deíctico propio de cada uno de los pronombres: proximidad del locutor, en el caso de esto, vs. proximidad del interlocutor o distancia respecto de ambos, en el caso de eso. Se observará sin embargo que, tal como sugiere la Nueva gramática de la lengua española, esos sentidos de mayor o menor proximidad espacial se reinterpretan aquí como grados de proximidad o de implicación subjetiva del locutor respecto de la representación discursiva evocada en $X$. Así, independientemente de la distancia física entre $X$ y el productor efectivo del enunciado, la ocurrencia de esto, que $X$ sugiere siempre una mayor cercanía subjetiva ( $X$ queda incorporado dentro del mismo espacio enunciativo del locutor) frente a eso, que $X$, que implica un menor grado de involucramiento $(X$ queda representado como más distante en la escena enunciativa donde se encuentran locutor y alocutario). En este sentido, (1a) y (2a) constituyen paráfrasis posibles de (1) y (2):

(1) a. A-. Pero ¿a vos qué te molesta?

B-. Esto, que estoy o que estamos viendo, como dentro de nuestro mismo espacio enunciativo, que saquen la basura.

(2) a. A-. Estás muy callada ¿Hay algo que te tenga mal?

(2) a. B-. Eso [señalando un montón de ropa tirada del marido], que estoy viendo, como exterior a mi espacio enunciativo, que el desorden sea permanente en esta casa.

\subsection{El evidencial anafórico-citativo esto/eso, que $X$}

Si en (1) y (2), el valor deíctico-ostensivo ad oculos (Bühler, 1934) de esto/eso obliga a recuperar el origen del punto de vista evidencial en la representación del entorno perceptivo de la situación de enunciación, el valor ostensivo-anafórico que esto/eso pueden adquirir en otros contextos, como ocurre de hecho en (10), (11) y (12), obliga a recuperar el origen del punto de vista introducido en un discurso previo, por lo que el significado evidencial es de tipo indirecto y citativo. En otras palabras, la relación de mutua afectación semántica entre la representación $X$ vehiculada por la aposición explicativa y el pronombre neutro con función ostensivo-anafórica es la que habilita la lectura citativa asociada a este tipo particular de empleos.

(10) A-.A mí la inseguridad me saca. Ya no se puede andar por la calle.

B-Pero ¿a vos qué te preocupa exactamente?

$A$-Esto, que te pueden robar en cualquier momento. (Corpus oral propio) 
(11) Otra PERSONA. - María iba a pasar muchos veranos a... Inf. - A Vera de Bidasoa. Enc. - ¿A la casa de Baroja? Inf. - Sí, sí, sí, mucho, mucho. Pues puedo decir una cosa, en fin, que..., que se aburría bastante, a no ser que llegase alguien que le hablase de sus obras. Entonces estaba el hombre derretido. Enc. - ¿Cómo le describiría usted si tuviera que hacer su biografía? Inf. - Pues, pues eso, que era egoísta y que toda aquella sencillez... (Corpus del español)

(12) Enc. - Sí, realmente hoy aquí hay muchos periodistas graduados que no encuentran trabajo, $y$ sin embargo ahi se presentan gentes que no tienen ni bachillerato. Inf.b. - Sí. Inf.a. - Eso. Inf.b. - Ni el bachillerato tienen, y... y que hablan muy mal el castellano y a más de eso... Enc. - Analfabetas. Inf.b. - lo más grave es eso, que son completamente analfabetas. (Corpus del español)

Ahora bien, tal como lo ponen de manifiesto las paráfrasis (10a), (11a) y (12a), ese discurso citado puede ser un discurso previo ya del propio locutor (10a) y (11a), ya del interlocutor (12a):

(10) a. A-.Esto, que acabo de decir, que te pueden robar en cualquier momento.

(11) a. A-.Eso, lo que dije (sugerí) antes, que era egoísta...

(12) a. B-. Eso, lo que Ud. dijo, que son completamente analfabetas.

Aunque al igual que en (1) y (2), la alternancia esto/eso manifiesta distintos grados de implicación subjetiva, en (10), (11) y (12), dichos grados deben reanalizarse de modo diferente según que el discurso citado sea propio o ajeno.

En (10), el mayor grado de implicación subjetiva señalado por esto debe releerse como reactualización del propio discurso citado (cf. 10b). En (11) la mayor distancia indicada por eso debe, por su parte, interpretarse como una instrucción para recordar un discurso ya dicho por el locutor y por lo tanto conocido por el interlocutor (cf. 11b):

(10) b. Esto, ya lo dije y lo vuelvo a decir ahora, que te pueden robar en cualquier momento.

(11) b. Eso, lo que acabo de decir (sugerir) y que, por lo tanto, Ud. ya sabe, que era egoísta...

En cuanto a (12), se observará que si bien tanto eso como esto resultan posibles para señalar que la fuente de $X$ es un discurso previo del interlocutor, solo eso puede funcionar autónomamente (i.e., sin acompañamiento de ningún gesto ostensivo) en este contexto. Tal como lo muestra la paráfrasis (12b),

(12) b. Eso, lo que Ud. dijo y que yo retomo ahora, que son completamente analfabetas.

la enunciación de Eso, que $X$ presenta un locutor que no solo rememora el discurso que cita, sino que también indica su procedencia (el interlocutor).

En cambio, para que el deíctico esto sea posible en el contexto de (12), es necesario que su enunciación esté acompañada de un gesto ostensivo hacia el otro o de una glosa aclaratoria que indique que el origen de ese discurso es el interlocutor. De lo contrario, y dado que esto indica siempre un grado máximo de implicación personal, la 
enunciación de ese deíctico en (12), sin gesto y sin glosa, obligaría a interpretar que la cita evocada procede del propio locutor. Se mostraría así una falta de registro de lo dicho previamente por el otro, lo que, a su vez, estaría en el origen de un posible conflicto conversacional. Acompañado en cambio de esos signos, que indican efectivamente que el origen del discurso citado es el otro, el sentido vehiculado por la enunciación de esto, que $X$ supone no solo el reconocimiento del discurso ajeno, sino también su reapropiación actualizada por parte del locutor (cf. 12c). Y en esta indicación reside precisamente el sentido de máxima empatía que surge toda vez que se enuncia esto, que $X$ para retomar un discurso ajeno.

(12) c. Esto [gesto ostensivo al interlocutor], lo que Ud. acaba de decir y con lo que yo acuerdo, que son completamente analfabetas.

\section{El evidencial citativo esto/eso de que $X$}

Un tercer grupo de ejemplos con esto/eso como marcadores de evidencialidad es el constituido por aquellas estructuras en las que el pronombre neutro aparece seguido, esta vez, de una aposición especificativa. En este caso, la aposición está encabezada por la preposición de, que introduce como término una cláusula subordinada sustantiva, tal como se ejemplifica en (3) y (4), que reiteramos:

(3) [Contexto situacional: discurso parlamentario en Cámara de Senadores]

No voy a reiterar esto de que ya no tenemos tiempo de discutirlo, de hacer modificaciones, como ya dijeron en otras ocasiones los señores senadores.

(4) [Contexto situacional: un padre pide explicaciones a su hijo] ¿Cómo es eso de que te vas mañana?

De modo análogo a (10), (11) y (12), las estructuras esto/eso de que $X$ presentes en (3) y (4) ponen de manifiesto que la representación discursiva evocada en $X$ es una cita procedente de un discurso previo. De hecho, en (3) el verbo reiterar alude a un decir previo que, tal como indica la glosa atributiva (como ya dijeron en otras ocasiones los señores senadores), encuentra su origen en discursos previos de otros locutores. Por su parte, en (4), las paráfrasis posibles (4a) y (4b) permiten poner en evidencia que el origen del punto de vista evidencial puede hallarse en un discurso previo del interlocutor (como dijiste) o de voces impersonales no identificadas (como dicen/como andan diciendo por ahî):

(4) a. ¿Cómo es eso de que, como dijiste, te vas mañana?

(4) b. ¿Cómo es eso de que, como dicen/como andan diciendo por ahí, te vas mañana?

Así, a diferencia de (10), (11) y (12), en los ejemplos (3) y (4), la fuente de $X$ no se recupera anafóricamente de la situación enunciativa, sino que se alude a dicha fuente por medio de la evocación de discursos conocidos más o menos lejanos de la escena de enunciación, es decir, no necesariamente pronunciados con anterioridad en el intercambio puntual en el que esto/eso aparecen usados. Esta alusión más difusa a 
discursos previos es producto de un nuevo desplazamiento semántico visible en el modo en que se interpreta el significado deíctico propio de los pronombres analizados: si en (1) y (2) la deixis ostensiva ad-oculos favorecía una interpretación evidencial directa, y en (10), (11) y (12) ese significado deíctico se reinterpretaba como la señalización anafórica hacia un discurso previo, en el caso de (3) y (4) nos encontramos frente a un caso de deixis evocadora. En este tipo de deixis, el valor espacial del demostrativo neutro (i.e., mayor o menor distancia respecto del locutor) se diluye, como en el caso de esto/eso, que $X$ anafórico-citativo, a favor de distintos grados de subjetivización del discurso citado. Así pues, si la enunciación de esto subjetiviza el discurso citado como más actual o más presente en la situación en la que se lo retoma, la ocurrencia de eso marca que el locutor se limita a comentar un discurso que rememora en el momento en que lo cita. Al respecto puede compararse (4) con (3) y con (13):

(13) ¿Esto de que no puedas venir a tomar el examen a mí me mata! (Corpus oral propio)

En efecto, mientras que en (4), el locutor refiere el discurso del interlocutor o de otros locutores más o menos identificados en la situación discursiva de la que se trata recordándolo mediante eso de que X, en (3) y (13) la ocurrencia de esto de que $X$ marca que el locutor refiere ese discurso trayéndolo a la situación de enunciación actual y con efectos subjetivos totalmente vigentes en ella ${ }^{6}$.

Como puede observarse, en este tercer grupo de estructuras evidenciales con los demostrativos neutros esto/eso, el significado ostensivo (deíctico o anafórico) ya no está necesariamente presente. Sí permanece en cambio una instrucción semántica más abstracta que obliga al interpretante a buscar y reconocer algo (cf. un decir o un saber) ya conocido en el universo de discurso compartido por locutor y alocutario. De este modo, en Esto/eso de que $X$, el contenido semántico $X$ ya no aparece ostensivamente señalizado ni como constatable por vía de la percepción (como ocurre en (1) y (2)), ni como procedente de un discurso efectivo recuperable de la misma escena de enunciación (como es el caso en (10), (11) y (12)). Y es precisamente la posibilidad de anular la ostensión al objeto de la deixis o de la anáfora lo que favorece el significado evidencial citativo pleno de esto/eso de que $X$.

Ahora bien, la indicación que insta a recuperar discursos conocidos, no necesariamente pronunciados antes en la escena de enunciación en la que aparecen evocados, se explica, en parte, por el condicionamiento sintáctico que supone este tipo particular de estructuras apositivo-especificativas: la aposición $X$ aparece introducida por la preposición $d e$, que restringe y circunscribe el alcance del demostrativo neutro. En este sentido, las estructuras esto/eso de que $X$ se asemejan a aquellas con el artículo neutro lo (cf. (14) y (15)) que codifican un significado factivo similar (Bosque y Moreno, 1990; Eguren, 1999):

\footnotetext{
${ }^{6}$ Una diferencia de sentido similar (-/+ vigencia subjetiva) es la que se expresa en la alternancia Pretérito Perfecto Simple (PPS) y Pretérito Perfecto Compuesto (PPC) en el español rioplatense (García Negroni, 1999).
} 
(14) Lo/Eso de levantarme pronto me sienta fatal.

(15) Lo/Eso de que le llamen tonto no le gusta nada. [ejemplos tomados de Eguren, 1999: 948]

En efecto, estas estructuras factivas admiten paráfrasis como (14a) y (15a), en las que el artículo neutro lo y los demostrativos esto/eso pueden ser reemplazados por una descripción definida cuyo núcleo es un sustantivo que alude a discursos o a saberes presentados como conocidos (tema, asunto, cuestión, etc.). Se observará que con este sustantivo se hace explícito y se refuerza, en el plano de lo expuesto, el punto de vista del presupuesto de esos enunciados: tener que levantarme pronto, en (14), y le llaman tonto, en (15).

(14) a. El/este tema de tener que levantarme pronto me sienta fatal.

(15) a. El/este asunto de que le llamen tonto no le gusta nada.

Ahora bien, dado que, como adelantamos, en esto/eso de que $X$ el origen de la representación $X$ ya no está ostensiblemente señalizada (ni deíctica ni anafóricamente), $X$ queda habilitada para remitir a distintos orígenes posibles. Consideremos en primer lugar los casos con esto de que X. En (3), la fuente es un colectivo de locutores identificados, los señores senadores, en (13) es el interlocutor (cf. 13a), en (18) es la doxa (cf. 18a) y en (19), un rumor (cf. 19a).

(3) No voy a reiterar esto de que ya no tenemos tiempo de discutirlo, de hacer modificaciones, como ya dijeron en otras ocasiones los señores senadores. (CREA, oral, Argentina, 1998)

(13) ¡Esto de que no puedas venir a tomar el examen a mí me mata! (Corpus oral propio)

(13) a. ¡Esto de que, como dijiste, no puedas venir a tomar el examen a mí me mata!

(18) Nunca pero nunca voy a tener buen trato con los niños pequeños. Siempre terminan llorando o golpeados. No me sale ese carisma digno de una maestra jardinera, la verdad no sirvo para eso. Desde siempre quise ser tía... pero todo esto de que primero tienen que ser chicos no va. Yo quiero ser «la tía copada» pero así no puedo. Ajó, ajó, ¿dónde está Nachito? aca taaaaaaaaaa... nah. Yo quiero que me digan «tía, convencela a mi vieja de que me deje ir a bailar»... o «tía, ¿cómo es estar en pedo? o tía, ¿quién fue el Che Guevara? o ¿por qué Perón era malo?" (CREA, efímero, Weblog, Argentina, 2003)

(18) a. Desde siempre quise ser tía... pero todo esto de que, como se dice, primero tienen que ser chicos no va. Yo quiero ser «la tía copada» pero así no puedo.

(19) Lo que no se ha cotizado en el mercado, quizá porque no sea cierto, es esto de que la banca está con el Gobierno. En otras épocas un refrendo de este tipo habría originado un alza notoria. Hoy, prácticamente ha pasado inadvertido, seguramente porque los operadores importantes saben hasta qué punto es verdad. (CREA, Prensa, España, 1977)

(19) a. Lo que no se ha cotizado en el mercado, quizá porque no sea cierto, es esto de que, como se rumorea, la banca está con el Gobierno. 
Ahora bien, si examinamos (20), se notará que no siempre la enunciación de esto de que $X$ permite introducir, bajo la forma de una paráfrasis, una glosa que aluda a un decir previo (i.e., como se dice, como dicen, como dijiste). Así, (20a) resulta relativamente extraño.

(20) ¿Cómo ve su marido esto de que usted sea un personaje público que aparece todas las mañanas en la televisión? (CREA, Prensa, Chile, 1997)

(20) a. \# ¿Cómo ve su marido esto de que, como se dice, usted sea un personaje público que aparece todas las mañanas en la televisión?

¿Esta extrañeza que produce (20a) pone en cuestión la hipótesis planteada al inicio de este apartado, según la cual esto de que $X$ codifica siempre un significado evidencial citativo? Desde nuestro punto de vista, la hipótesis puede mantenerse sin problemas, si se admite que la fuente a la que alude la enunciación de esto de que $X$ puede mostrarse de dos modos diferentes en el enunciado: o bien bajo la forma de un decir, o bien bajo la forma de un saber. Así, a diferencia de (20a), (20b) constituye, como paráfrasis de (20), un enunciado fácilmente interpretable.

(20) b. ¿Cómo ve su marido esto de que, como se sabe, usted sea un personaje público que aparece todas las mañanas en la televisión?

En relación con la representación semántica de la voz del SE, Anscombre (2005) ha llamado la atención sobre los múltiples valores que puede adquirir el $S E$ en tanto personaje enunciativo. Esta multiplicidad, según el análisis del autor, se evidencia a través de la puesta en relación entre el tipo de discurso generalizante evocado (i.e., un decir o un saber) y la posibilidad o no de inclusión del locutor dentro del colectivo de personajes de discurso que dicen o saben. Así, tal como demuestra Anscombre, un enunciado del tipo Se dice que Luis XI era un gran rey, pero yo no lo creo es totalmente posible, mientras que Se sabe que Luis XI era un gran rey, pero yo no lo creo no lo es. Estos ejemplos permiten ver así que, por medio de un movimiento contraargumentativo, el locutor puede señalar su no inclusión dentro de la voz colectiva del $S E$ ( $\mathrm{ON}^{7}$-Locuteur, en términos de Anscombre) cuando se trata de un decir, pero no puede excluirse de ese $S E$ si el origen de esa voz es un saber colectivo que a la vez se cita.

Lejos de quebrantar entonces la hipótesis inicial sobre el carácter evidencial de la estructura esto de que $X$, las observaciones de Anscombre van en nuestro mismo sentido. En efecto, esto de que $X$ no solo codifica que la fuente de $X$ es un discurso previo, presupuesto y conocido por ambos interlocutores ${ }^{8}$, sino que también brinda instrucciones acerca de los grados de cristalización de ese discurso: puede tratarse de un decir (del que el locutor puede distanciarse) o de un saber (del que el locutor no puede excluirse). Así, en (18), que reiteramos para comodidad del lector, el locutor puede alejarse del punto de vista doxal sobre las funciones de una tía (esto de que $X$ alude a lo

\footnotetext{
${ }^{7}$ Para un estudio pormenorizado del ON en francés puede consultarse Fløttum, Jonasson y Noren, 2007.

${ }^{8}$ Usted es un personaje público que aparece todas las mañanas en la TV es un contenido presupuesto, que en (20) aparece reforzado por la presencia de esto de que.
} 
que se dice respecto de ese rol familiar), mientras que en (21), ese distanciamiento resulta imposible. Dar más importancia al actor que al autor o al director es un discurso presentado en (21) como algo que se sabe y no que se dice (cf. la posibilidad de (21a) y la dificultad de (21b)):

(18) Nunca pero nunca voy a tener buen trato con los niños pequeños. Siempre terminan llorando o golpeados. No me sale ese carisma digno de una maestra jardinera, la verdad no sirvo para eso. Desde siempre quise ser tía... pero todo esto de que primero tienen que ser chicos no va. Yo quiero ser «la tía copada» pero así no puedo. Ajó, ajó, ¿dónde está Nachito? aca taaaaaaaaaa... nah. Yo quiero que me digan «tía, convencela a mi vieja de que me deje ir a bailar»... o «tía, ¿cómo es estar en pedo? o tía, ¿quién fue el Che Guevara? o ¿por qué Perón era malo?" (CREA, efímero, Weblog, Argentina, 2003)

(21) Fue bueno esto de que en cierto momento se le diera más importancia al actor que al autor o al director, en contra de la tiranía tradicional hasta 1960. Pero actualmente los grupos se dan cuenta de que se necesita un dramaturgo. (CREA, Prensa, Chile, 1979)

(21) a. Fue bueno esto de que, como se sabe, en cierto momento se le diera más importancia al actor que al autor o al director, en contra de la tiranía tradicional hasta 1960. Pero actualmente los grupos se dan cuenta de que se necesita un dramaturgo. (CREA, Prensa, Chile, 1979)

(21) b. \#Fue bueno esto de que, como se dice, en cierto momento se le diera más importancia al actor que al autor o al director, en contra de la tiranía tradicional hasta 1960. Pero actualmente los grupos se dan cuenta de que se necesita un dramaturgo. (CREA, Prensa, Chile, 1979)

¿Pero qué ocurre cuando en lugar de esto aparece eso en la estructura evidencial bajo análisis? Si, según el caso, al igual que esto, eso puede evocar ya un decir (cf. 22) y su paráfrasis (22a), ya un saber (cf. 23) y su paráfrasis (23a),

(22) A-. Detrás de la vida, no solo de mis letras. Detrás de cualquier cosa que uno haga siempre hay mujeres.

$B-. ¿$ Se refiere a eso de que «detrás de un gran hombre hay una gran mujen»?

A-. Sí, pero yo no soy un gran hombre. (CREA, Prensa, El Tiempo, Colombia, 1997)

(22) a. B-.¿Se refiere a eso de que, como se dice, "detrás de un gran hombre hay una gran mujer»?

A-. Sí, pero yo no soy un gran hombre. (CREA, Prensa, El Tiempo, Colombia, 1997)

(23) Me gusta la comida marroquí aunque no mucho eso de que se tenga que comer con las manos.

(23) a. Me gusta la comida marroquí aunque no mucho eso de que, como se sabe, se tenga que comer con las manos.

el rasgo semántico diferencial que introduce eso de que $X$ es, una vez más, de tipo 
modal. Mientras que con la enunciación de esto de que $X$ se revitaliza y reactualiza un discurso previo (i.e., cristalización de un saber o de un decir), con eso de que $X$ se alude a ese decir o a ese saber como si se lo recordara en la escena actual de enunciación.

\section{Consideraciones finales}

A lo largo de este trabajo, hemos intentado dar cuenta del significado evidencial contenido en las estructuras esto/eso, que X/de que $X$, estructuras que hasta aquí no han recibido un tratamiento particularizado. Nuestro objetivo fue poner de manifiesto que los significados codificados por estas construcciones van desde la señalización de una fuente directa perceptiva hasta la indicación de una fuente indirecta: un discurso citado o evocado. Tal como lo sugiere nuestro trabajo, la gradación que se produce entre los distintos tipos de significado evidencial se relaciona, sin duda, con la pérdida gradual del significado deíctico (no así del modal) de los pronombres demostrativos presentes en estas estructuras:

\begin{tabular}{|c|c|}
\hline \multicolumn{2}{|c|}{ Significado evidencial perceptivo directo «ad-oculos» (cf. (1) y (2)) } \\
\hline Esto, que $\boldsymbol{X}$ (aposición explicativa) & Eso, que $\boldsymbol{X}$ (aposición explicativa) \\
\hline + gesto ostensivo a $X$ & + gesto ostensivo a $X$ \\
\hline+ implicación subjetiva & - implicación subjetiva \\
\hline
\end{tabular}

\begin{tabular}{|c|c|}
\hline \multicolumn{2}{|c|}{ Significado evidencial anafórico-citativo del propio discurso (cf. (10) y (11)) } \\
\hline Esto, que $\boldsymbol{X}$ (aposición explicativa) & Eso, que $\boldsymbol{X}$ (aposición explicativa) \\
\hline+ prosodia ostensiva & + prosodia ostensiva \\
\hline + reenunciación del discurso previo & + recuerdo del discurso previo \\
\hline
\end{tabular}

\begin{tabular}{|c|c|}
\hline \multicolumn{2}{|c|}{ Significado evidencial anafórico-citativo del discurso ajeno (cf. (12)) } \\
\hline Esto, que $\boldsymbol{X}$ (aposición explicativa) & Eso, que $\boldsymbol{X}$ (aposición explicativa) \\
\hline + gesto ostensivo al $(X$ del) interlocutor & +/- gesto ostensivo al ( $X$ del) interl. \\
\hline + reapropiación del discurso ajeno & + recuerdo del discurso ajeno \\
\hline
\end{tabular}

Significado evidencial indirecto citativo de un decir o de un saber (cf. (13), (18), (19), (20), (21) y (22))

\begin{tabular}{|c|c|}
\hline Esto de que $\boldsymbol{X}$ (aposición especificativa) & Eso de que $\boldsymbol{X}$ (aposición especificativa) \\
\hline - ostensión (ni gestual ni prosódica) & - ostensión (ni gestual ni prosódica) \\
\hline + reactualización del discurso evocado & + recuerdo del discurso evocado \\
\hline
\end{tabular}

Pero como hemos intentado demostrar a lo largo del trabajo, los distintos tipos de significado evidencial codificados en estas estructuras también se relacionan con el tipo 
de estructura apositiva (explicativa o especificativa) que les sigue. En cuanto a la interpretación evidencial indirecta, hemos distinguido dos casos. En el primero, la aposición es explicativa y el pronombre conserva algo de su significado ostensivo, por lo que la fuente debe buscarse en un decir previo e identificable en la situación de enunciación. Hemos denominado este empleo «evidencial indirecto anafórico-citativo».

\begin{tabular}{|l|}
\hline Esto/eso, que $\mathbf{X}$ (aposición explicativa) \\
\hline$>$ Significado evidencial indirecto anafórico-citativo de un decir \\
\hline
\end{tabular}

En el segundo caso, la aposición es especificativa y esto/eso solo conservan el valor modal. Aquí, y ya desprovista de su significado ostensivo (deíctico o anafórico), la estructura esto/eso de que $X$ favorece una interpretación citativa que, a diferencia de lo que afirma Santos Río (2003):

a) no se limita necesariamente a la identificación de discursos efectivamente pronunciados;

b) el discurso evocado puede proceder de distintas fuentes discursivas (el propio locutor, el interlocutor, un colectivo identificado o no de locutores, la doxa, etc.)

c) el discurso evocado puede proceder de un decir pero también de un saber.

Esto/eso de que $\mathrm{X}$ (aposición especificativa)

$>$ Significado evidencial indirecto citativo de un decir o de un saber

Una última observación para concluir se refiere a las diferencias semánticas que surgen de la ocurrencia de esto o eso en estas estructuras evidenciales. Si, como afirma la Nueva gramática, ellas se relacionan en todos los casos con los aspectos modales de mayor o menor implicación subjetiva, hacemos notar que esa subjetivización difiere según la evidencialidad sea directa (esto/eso, que X) o indirecta (esto/eso, que X; esto/eso de que $X)$. En el primer caso, esto señala mayor cercanía subjetiva ( $X$ queda incorporado dentro del mismo espacio enunciativo del locutor) frente a eso, que implica un menor grado de involucramiento ( $X$ queda representado como más distante en la escena enunciativa). Por su parte, en los casos de evidencialidad indirecta, el significado modal presente en esto y eso se reanaliza respectivamente como grados de actualización o de rememoración del discurso evocado.

Recibido: 09.05.2014

Aceptado: 02.09.2014

\section{Referencias bibliográficas}

Aikhenvald, A. (2004): Evidentiality. Oxford, Oxford University Press.

Anderson, L. (1986): «Evidentials, Paths of change and Mental Maps: Tipologically Regular Asymmetries». En Chafe, W. \& J. Nichols (eds.): Evidentiality: The Linguistic Coding of Epistemology. Norwood, Ablex, págs. 273-312. 
Anscombre, J.-C. (2005): «On-Locuteur: une entité aux multiples visages». En J. Brès et al. (eds.): Dialogisme et polyphonie. París, De Boeck Supérieur, págs. 75-94.

Bermúdez, F. (2005): Evidencialidad. La codificación lingüística del punto de vista. Tesis doctoral, Departamento de Español de la Universidad de Estocolmo.

Boas, F. (1947): «Kwakiutl grammar, with a glossary of the suffixes». Transactions of the American Philosophical Society 37, págs. 201-377.

Bühler, K. (1934): Sprachtheorie. Die Darstellungsfunktion der Sprache. Jena, Gustav Fischer.

Carranza, I. (2007): «La construcción de la evidencia». En Vallejos Llobet, P. (coord.): Los estudios del discurso. Nuevos aportes desde la investigación en la Argentina, Bahía Blanca, Ediuns, págs. 17-36.

Chafe, W. (1986) «Evidentiality in English Conversation and Academic Writing». En Chafe, W. \& J. Nichols (eds): Evidentiality: The Linguistic Coding of Epistemology. Norwood, Ablex, págs. 261-272.

Ducrot, O. (1984): Le dire et le dit. París, Minuit.

Ducrot, O. (1990): Polifonía y argumentación. Cali, Universidad del Valle-Cali.

Ducrot, O. (2004): Sentido y argumentación. En Arnoux, E. y M. M. García Negroni (comps.): Homenaje a Oswald Ducrot. Buenos Aires, Eudeba, págs. 359-370.

Eguren, L. (1999): Pronombres y adverbios demostrativos. Las relaciones deícticas. En Bosque, I. y V. Demonte (eds.): Gramática descriptiva de la lengua española. Madrid, Espasa, págs. 930-972.

Fløttum, K., Jonasson, K., Norén, C. (2007): ON - pronom à facettes. Bruselas, Duculot-De Boeck.

Fuentes Rodríguez, C. (2009): Diccionario de conectores y operadores del español. Madrid, Arco Libros.

García Negroni, M.M. (1999): «La distinción Pretérito Perfecto Simple / Pretérito Perfecto Compuesto. Un enfoque discursivo». Discurso y Sociedad, 1 (2), págs. 45-60.

García Negroni, M.M, Montero, A.S. y Libenson, M. (2014): «De la intención del sujeto hablante a la representación polifónica de la enunciación. Acerca de los límites de la noción de intención en la descripción del sentido». Revista de Investigación Lingüística, 16 , en prensa.

Jakobson ([1957] 1971). «Shifters, verbal categories and the Russian verb». En Selected Writings Vol 2. Cambridge, Cambridge University. The Hague, Mouton, págs. 130-147.

Mushin, I. (2001): Evidentiality and Epistemological Stance. Narrative Retelling. Ámsterdam/ Filadelfia, John Benjamins.

Real Academia Española. (1999): Gramática descriptiva de la lengua española. Madrid, Espasa.

Real Academia Española. (2010): Nueva gramática de la lengua española. Madrid, Espasa.

Reyes, G. (1994): Los procedimientos de cita: citas encubiertas y ecos. Madrid, Arco Libros.

Santos Río, L. (2003): Diccionario de partículas. Salamanca, Kadmos.

Willet, T. (1988): «A cross-linguistic survey of the grammaticalization of evidentiality». Studies in Language, 12, págs. 57-91. 